\title{
AS LÍNGUAS FALADAS NAS COMUNIDADES RURAIS NIPO- BRASILEIRAS DO ESTADO DE SÃO PAULO E A PERCEPÇÃO DAS TRÊS GERAÇÕES SOBRE A 'MISTURA DE LÍNGUAS'
}

Junko Ota

RESUMO: O presente texto tem por finalidade traçar um quadro geral das línguas faladas nas comunidades rurais nipo-brasileiras do estado de São Paulo, focando a percepção das três gerações sobre a prática de mistura das línguas japonesa e portuguesa nas suas falas, que ocorre notadamente no ambiente familiar.

PALAVRAS-CHAVE: Comunidade nipo-brasileira; mistura de línguas; língua da colônia (koronia-go)

Estima-se que a população nipo-brasileira (ou nikkei) no Brasil chega a 1.400 .000 pessoas, que corresponde a $52,7 \%$ dos imigrantes nikkeis fora do Japão, segundo dados de $2007^{1}$, o que faz do contingente brasileiro o maior de todos os países com a presença dos japoneses e seus descendentes, excetuando o próprio Japão. No ano de 2008 , quando a imigração japonesa completa um século no Brasil, desde a chegada de Kasato-maru no porto de Santos, muitos aspectos estão sendo discutidos sobre essa comunidade nipo-brasileira, a começar pela sua história da imigração, a trajetória no país enquanto imigrantes, suas atividades econômicas, a inserção social no país etc..

Um dos aspectos ligados à imigração japonesa que nos chamam a atenção é a língua dos imigrantes e de seus descendentes. $O$ contato da língua japonesa, trazida pelos

1. "Shiryôhen: Nichi, Chûnanbei kankei" (Dados: Relações entre o Japão e a América Central e do Sul). In Gaikôforum (Fonum Internacional). 10/2007, no. 231, p.70. 
imigrantes que nasceram no Japão, com a portuguesa, língua oficial do Brasil, resultou numa língua chamada "koronia-go"(língua da colônia) ou "nissei-go"(língua do nissei), abordado pelos vários trabalhos precedentes, tais como Andô (1956), Handa (1970), Mase (1987), Nawa (1988), Kuyama (2000) e outros. Trata-se de uma variante da língua japonesa, em que se vê claramente a interferência do português, desde a adoção dos empréstimos lexicais até mudança de códigos.

O presente artigo tem por finalidade apontar alguns dados relevantes sobre o comportamento lingüístico dos falantes de duas comunidades rurais paulistas, abrangendo pessoas de primeira a terceira gerações, baseando-se nos dados coletados na primeira fase do projeto de pesquisa, realizada pelos pesquisadores da Universidade de Osaka e das universidades brasileiras, em 2003. Integrado no Projeto Interface das Humanidades - Center of Excelence (COE) Program da Universidade de Osaka, o levantamento foi realizado com o intuito de obter dados lingüísticos das diferentes gerações dos imigrantes e seus descendentes nas comunidades nipo-brasileiras. Para a efetivação do projeto, foram eleitas duas comunidades rurais paulistas constituídas de imigrantes japoneses e seus descendentes, a saber: Vila Ipelândia, chamada também de "Fukuhaku-mura" em japonês, localizada próxima à capital, e Comunidades Aliança, que correspondem a Primeira Aliança, Segunda Aliança e Terceira Aliança, no interior paulista, distante da capital.

A Vila Ipelândia localiza-se a $34 \mathrm{~km}$ da capital, no município de Suzano, hoje integrada dentro da área de cinturão verde da região suburbana da capital, com 512 habitantes no levantamento de $2002^{2}$, e a comunidade Aliança encontra-se no município de Mirandópolis, região noroeste do estado, a $580 \mathrm{~km}$ da capital, próxima à divisa com o estado de Mato Grosso do Sul, com 644 habitantes. Ambas são comunidades antigas, fundadas entre 1926 e $1931^{3}$, antes do período de segunda guerra mundial.

O projeto foi dividido em duas fases: a primeira consistiu na aplicação de questionário de 68 perguntas, abrangendo dados pessoais, questões sobre a aprendizagem de japonês e português, auto-avaliação da proficiência lingüística em duas línguas, as línguas faladas com os membros da família e a percepção sobre as línguas em uso; e a segunda fase foi dedicada para a gravação de entrevistas dos informantes em número reduzido. Para a primeira fase de pesquisas, foram selecionados 219 informantes,

2. Segundo Nikkei shakai jittai chôsa hôkokusho (Relatório das pesquisas sociais das comunidades nipo-brasileiras), editado pelo Centro de Estudos Nipo-Brasileiros, em 2002. O número de habitantes de Aliança também se baseia no mesmo relatório.

3. A Primeira Aliança foi habitada pelos primeiros imigrantes japoneses em 1926, a Segunda Aliança e a Terceira Aliança, em 1927; já a Vila Ipelândia recebeu os primeiros japoneses em 1931 (OTA, J \& MORALES, L.M. 2003). 
sendo 108 da Vila Ipelândia e 111 da Aliança, que, separados em gerações, eram 80 da primeira geração, ou nascidos no Japão, 83 da segunda geração e 56 da terceira geração (doravante, isseis, nisseis e sanseis, respectivamente). Todos os informantes responderam ao questionário, cujas respostas foram preenchidas pelos entrevistadores ${ }^{4}$

As faixas etárias das três gerações variam, mas a que predominou entre os isseis foi de $42 \%$, de 74 a 83 anos; a de nisseis, $36,1 \%$ na faixa de 54 a 63 anos, e a de sanseis, $42,9 \%$ com a idade entre 24 e 33 anos, o que caracteriza claramente a alta faixa etária dos isseis, em contraste com os sanseis, mais jovens.

Um dos trabalhos apresentados anteriormente, baseados nos dados de pesquisa, abordou a relação entre os domínios e as gerações (OTA \& GARDENAL, 2006). Para a pergunta "Que língua(s) falavam na sua família quando você era criança?", os nisseis que responderam "Japonês" ou "Mais japonês"5 somaram 72,3\% em média de duas comunidades. Os mesmos nisseis, ao responderem qual língua falavam num jantar em família, na ocasião do questionário, 42,9\% deram a mesma resposta. Já no contexto familiar para os sanseis, constata-se menos uso de língua japonesa na infância e menor ainda na ocasião da pesquisa: $19,6 \%$, quando eram crianças, e $14,3 \%$ na ocasião do questionário. Vale ainda destacar que, na ocasião da entrevista, 19,6\% responderam então falar "Metade japonês e metade português" em familia, 26,8\% disseram "Mais português" e 39,3\% afirmaram falar "Português" Através desses números, pode-se constatar que de segunda a terceira geração, a fala em japonês ou com a predominância do japonês diminui, dando espaço para o português, com a porcentagem mais alta, seguida de fala com a predominância do português, e depois a presença de duas línguas na fala.

Quanto aos isseis, que nasceram no Japão, não lhes foi formulada a pergunta sobre a língua da família quando crianças (uma vez que a média da idade em que chegaram ao Brasil era de 14 anos), supondo que $100 \%$ ou a maioria das respostas fosse "Japonês", mas na ocasião da pesquisa, a média dos isseis em duas comunidades que responderam falar então em "Japonês" ou "Mais japonês" no encontro da família era de $64,9 \%$. Isso mostra claramente o contexto familiar já bastante diferente de quando os informantes eram crianças, uma vez a convivência com os que falam menos japonês faz com que o português esteja mais presente nas conversas.

Neste trabalho, pretendemos abordar as respostas dos informantes às questões $67 \mathrm{e}$ 68 da primeira fase do projeto, com perguntas sobre a mistura de duas línguas, a japonesa e a portuguesa no seu cotidiano com os familiares ou amigos, discriminando as gerações.

4. Maiores detalhes sobre o projeto no relatório, editado pela Universidade de Osaka, em 2004.

5. Havia 5 alternativas para resposta à pergunta, que foram: 1. Japonês; 2. Mais japonês; 3. Metade japonês e metade português; 4 . Mais português; 5 . Português. 
Doi (2007) tem analisado o mesmo tópico, porém enfocando as opiniões favoráveis em geral quanto à mistura de duas línguas, $\mathrm{e}$ as diferentes motivações que fazem os informantes adotarem a mistura de línguas. Neste artigo, porém, gostaríamos de tratar das respostas dos informantes, atrelando-as a cada uma das gerações.

A Questão 67 previa como resposta uma das três alternativas: Sim, Não ou Não sei, como mostram os quadros seguintes, dois com os números indicando as respostas dos informantes conforme a comunidade, seguidos de quadro 3 , com a média de duas comunidades:

Questão 67: Você mistura o japonês e o português quando fala entre família ou com amigos nikkeis?

Quadro 1: As três gerações da Aliança:

\begin{tabular}{|c|c|c|c|}
\hline & Isseis & Nisseis & Sanseis \\
\hline Sim & $75,6 \%$ & $90,5 \%$ & $82,1 \%$ \\
\hline Não & $22,0 \%$ & $9,5 \%$ & $17,9 \%$ \\
\hline Não sei & $2,4 \%$ & & \\
\hline
\end{tabular}

Quadro 2: As três gerações da Vila Ipelândia:

\begin{tabular}{|c|c|c|c|}
\hline & Isseis & Nisseis & Sanseis \\
\hline Sim & $76,9 \%$ & $97,6 \%$ & $85,7 \%$ \\
\hline Não & $23,1 \%$ & $2,4 \%$ & $14,3 \%$ \\
\hline Não sei & - & - & \\
\hline
\end{tabular}

Quadro 3: Média de duas comunidades:

\begin{tabular}{|c|c|c|c|c|}
\hline & Isseis & Nisseis & Sanseis & Média \\
\hline Sim & $76,3 \%$ & $94,0 \%$ & $83,9 \%$ & $84,9 \%$ \\
\hline Não & $22,5 \%$ & $6,0 \%$ & $16,1 \%$ & $14,6 \%$ \\
\hline Não sei & $1,3 \%$ & 0 & 0 & $0,5 \%$ \\
\hline
\end{tabular}

(baseados nos dados de Osaka University, 2004) 
Comparando os Quadros 1 e 2, da Aliança e Vila Ipelândia, respectivamente, observamos que os dois apresentam os números bastante próximos entre si, no que concerne às gerações, demonstrando haver pontos em comum, com a porcentagem de resposta afirmativa mais alta observada entre os nisseis, seguida de sanseis e depois de isseis. A resposta dos nisseis que afirmam misturar as duas línguas foi predominante, com a média de $94 \%$, atestando a clara consciência que têm com relação à mistura das mesmas na sua fala. Já a resposta positiva dos sanseis, que vêm em segundo lugar, contabiliza $83,9 \%$ dos informantes e os isseis com resposta positiva são $76,3 \%$. A média do total de informantes que afirmaram misturar as duas línguas, assim, é de 84,9\%, contra 14,6\% que disseram não fazê-lo.

Mesmo levando em conta de que se trata da auto-avaliação dos informantes, é significativo observar o número expressivo dos que têm consciência quanto à mistura de duas línguas na conversa no cotidiano, com os familiares de sua comunidade, o que nos leva a concluir que uma conversação com mistura de línguas japonesa e portuguesa é uma realidade no cotidiano da maioria dos informantes que compõem as duas comunidades rurais pesquisadas, sobressaindo mais na fala dos nisseis, dentre as três gerações.

A opinião dos informantes sobre a mistura de línguas foi solicitada na questão seguinte, que apresentamos a seguir.

\section{Questão 68: $\mathrm{O}$ que você acha sobre misturar o japonês e o português?}

Diferentemente da questão anterior, que previa a resposta com três alternativas, a questão 68 é uma pergunta aberta, que permite saber a opinião de cada um dos informantes, assim como avaliar o grau de percepção ou consciência da sua fala ou dos outros.

Diante dos números que foram apresentados a partir da questão 67 , pensamos na hipótese de que os nisseis aceitam mais a mistura de duas línguas, uma vez que eles responderam misturá-las mais, seguidos pelos sanseis e por fim pelos isseis, estes últimos porque eles, quando crianças, viviam no ambiente familiar com a fala predominante em japonês. Entretanto, os números calculados, baseados em Doi (2007), não chegaram a confirmar a nossa hipótese. Ainda segundo Doi, as respostas com avaliação positiva, incluindo as dos informantes que aceitam com certo conformismo, chegam a cerca de 74 $\%$ em média entre os isseis, os que mais aceitam a mistura de línguas, seguidos de sanseis, com $60 \%$, e por último os nisseis, com $54 \%$ de aceitação, como mostra o quadro abaixo:

Quadro 4: aceitação da mistura de línguas

\begin{tabular}{|c|c|c|c|c|}
\hline & Isseis & Nisseis & Sanseis & Média \\
\hline Aliança & $67,7 \%$ & $57,8 \%$ & $78,2 \%$ & $66,3 \%$ \\
\hline Ipelândia & $80,0 \%$ & $50,0 \%$ & $41,6 \%$ & $57,4 \%$ \\
\hline Média & $73,7 \%$ & $53,8 \%$ & $59,5 \%$ & $61,8 \%$ \\
\hline
\end{tabular}

(baseado na tabela de Doi, 2007) 
A média entre as três gerações de duas comunidades, de cerca de $62 \%$ de posicionamento favorável à mistura de línguas, é significativa, contrapondo-se a apenas $38 \%$ que revelaram ter opinião negativa sobre a prática. Analisando os motivos de aprovação dos $62 \%$ dos informantes, Doi afirma prevalecer "as justificativas de caráter pragmático" como a "conveniência e facilidade para a comunicação entre os falantes" A autora elenca as principais motivações dos que aprovam a prática de mistura de línguas, dividindo-as adequadamente em seis itens, seguidas de análise respectiva e exemplificando-as com os depoimentos dos informantes:

“a) um meio para a comunicação;

b) um resultado da falta de competência nas línguas envolvidas;

c) uma forma de acomodação à fala do interlocutor;

d) uma adequação ao contexto brasileiro;

e) uma expressão de cunho afetivo; e

f) uma expressão da identidade de nikkei brasileiro." (Doi, 2007: 248-52)

Gostaria de, neste artigo, destacar cada uma das gerações para tentar traçar o perfil, apontando tanto as atitudes favoráveis quanto as desfavoráveis com relação à mistura de línguas, exemplificando com as opiniões dos informantes ${ }^{6}$. Os dados entre colchetes após cada citação dos informantes indicam, em primeiro lugar, a procedência do mesmo em abreviatura (A para Aliança e I para Vila Ipelândia), seguida de abreviatura do sexo ( $\mathrm{M}=$ masculino ou $\mathrm{F}=$ feminino) e idade, e após o hífen se encontra o número do informante dentro de cada geração/comunidade. Por exemplo, [IF57-100] indica que o informante é da Ipelândia, sexo feminino, 57 anos, no. 100 da lista de sua geração:

Isseis - predominam as opiniões de que é natural ou normal misturar as duas línguas: "É comum misturar. É habitual e natural" [IM53-10], inclusive muitos afirmando que o uso de duas línguas na mesma fala é inconsciente.

A facilidade de comunicação é uma outra explicação: "Posso falar (em japonês) sem misturar, mas todos entendem melhor quando uso as palavras mais familiares (em português). Se mudo para o japonês, ficam sem entender."[AM73-55], provando nesse caso que a mistura é para se adequar ao interlocutor que não tem a proficiência suficiente para compreender a fala exclusiva em japonês. Outras respostas sobre a adequação da fala ao interlocutor: "Como o japonês é dificil, é natural que fale em português as palavras

6. Independente da língua em que responderam, as respostas dos informantes foram registradas em japonês em "Shiryôhen, Gengoseikatsu chôsa, daiichiji dêta" (Parte de Dados, Primeiros dados de Levantamento de Hábito Linguístico", no relatório sobre o projeto (Osaka University, 2004). É tradução nossa todas as opiniões citadas neste artigo. 
desconhecidas." [AM82-8] "Quando falo com pessoas jovens, misturo palavras em português para nomes de objetos. Ficou assim naturalmente." [IM85-26]. Nessas opiniões, fica claro que a mistura de línguas é uma opção levando em conta o interlocutor, e não necessidade do falante.

Na pesquisa de Doi (2007), os dados numéricos das respostas da questão 68 incluem os que responderam "não tem jeito" (shikataga nai), posição esta que é de conformismo ou uma aceitação passiva, dada a realidade que cerca o informante: "Como estou no Brasil, não tem jeito (se misturo)." [IM74-68]; "Acho que seria melhor se falassem só em japonês, mas não há jeito. Acho que misturam porque não sabem (determinadas palavras)." [IF76-20].

Essa posição se difere da dos que expressam opinião favorável à mistura de línguas, ressaltando a sua qualidade: "É bom que se use o koronia-go no dia-a-dia. É língua familiar."[AM71-4]; "Se for koronia-go, dá para falar descontraído. É uma língua familiar e calorosa, (...) sem a complexidade da linguagem de tratamento." [IM7398], definindo assim o koronia-go, comparando-o com a língua japonesa; "A conversa fica mais harmoniosa"[IM79-40]; "O japonês com mistura de português é como um dialeto."[AM70-46]; "A pronúncia do japonês é um pouco dura, mas o koronia-go fica mais melódico com a mistura do português." [AM60-86], definindo cada qual a 'língua da colônia' "O koronia-go nasceu com a necessidade da sociedade/grupo dos imigrantes. Não entendo os dialetos de Okinawa, Aomori nem Kagoshima. Em outras palavras, koroniago é a língua comum dos nikkeis.'[IM66-96]. Associados a essas opiniões, há aqueles que expressam um sentimento de "pertencimento" a um grupo com o mesmo histórico e realidade, uma comunidade lingüística, dentro da qual compartilham uma forma de pensar, de sentir a língua que falam: "Os nikkeis idosos misturam bastante (as línguas). É comum falar as palavras em português ou japonês." [IF78-106]; "Como toda a colônia usa as línguas misturadas, eu também uso inconscientemente." [IM58-84].

Por outro lado, há informante contra a mistura de línguas que se defende, com a seguinte opinião: "Se misturar, fica dificil de entender. Eu falo japonês para os japoneses, e português para os brasileiros." [IM89-9], demonstrando sua capacidade lingüística em duas línguas, e com determinação de usá-las distintamente.

Nisseis - para muitos dos nisseis, criados pelos isseis, em geral fluentes em japonês, e convivendo com seus filhos sanseis, que falam mais português, as duas línguas estão bastante presentes no seu cotidiano. Há muitas opiniões que consideram normal, natural ou habitual misturar as línguas, porque estão no Brasil, ou porque "há palavras que não têm tradução em japonês." [IM44-30].

Dentre os informantes que aceitam a mistura, pode-se observar o falante que declara sua proficiência em português e japonês: "É normal, porque tem que entender as duas." [IM61-32]. A proficiência bilíngue de certos informantes mostra diferenças quanto à 
forma de falar em cada uma das línguas: "Quando não sei como dizer (certas palavras) em japonês, misturo (o português). Quando falo em português, não misturo (...)."'[AF67-25]. No caso deste informante, a mistura de línguas ocorre somente quando está falando em japonês, complementando parcialmente com palavras em português, porém a vice-versa, ou seja, quando está falando em português, não acontece.

Comparando com outras gerações, há um número maior de informantes que afirmam falar de formas diferenciadas, conforme os interlocutores, que podem ser 1) japoneses do Japão, diferentes dos imigrantes isseis, 2) isseis, 3) nisseis, ou os da mesma faixa etária ou 4) sanseis, ou os mais jovens:

- exemplos de 1: "Para os japoneses do Japão, não misturo (as línguas), mas se o interlocutor é alguém que fala japonês e português, uso o koronia-go." [IM57100]; "É comum misturar as palavras. Quando falo com os japoneses (do Japão), tomo cuidado."[IM30-59];

- exemplos de 2 e 3: "Quando falo com os mais velhos, procuro não misturar, porque acho que é falta de respeito. Mas é difícil falar só em japonês"[AM43-59]; "Com os isseis, falo em japonês, mas quando falo com os que entendem o português, acabo misturando naturalmente." [AF57-27]; "Quando falo com os idosos, misturo, mas com os da faixa de minha idade, só em português." [AM33-58];

exemplo de 4: "Misturo muito quando falo com o meu filho, mas acho que não é muito bom. Seria melhor se falasse em japonês mais fácil." [AF63-37].

Percebe-se que, para falar com os japoneses do Japão, tenta-se falar o japonês; com os isseis idosos, fala em japonês ou, conforme a sua proficiência, mistura as duas línguas. $\mathrm{E}$ com os mais jovens, prevendo sua dificuldade em entender sua fala em japonês, mistura $o$ português. $O$ nissei pode ser ou bastante versátil, com sua competência bilíngue, adequando sua fala de acordo com o interlocutor, ou pode ter diferentes graus de proficiência conforme a língua. Um consegue falar em japonês com os isseis idosos, e outro fala em japonês, misturando o português, suprindo a falta de seu vocabulário.

Houve respostas que afirmaram ser necessário misturar as línguas: "os nisseis e sanseis têm pronúncia diferente da dos isseis. Se não misturar, não dá para conversar, nem entender." [AM66-11]. A necessidade tem a ver com a limitação na competência do próprio falante ou então do interlocutor: "Como me faltam palavras, uso (misturadas). É necessário porque tem palavras que não consigo traduzir adequadamente." [IF24-71]; "Quando se fala com nisseis, há quem não entende as palavras em japonês, portanto não importa se misturar o português." [IF56-95].

O número de nisseis que declararam misturar as duas línguas foi expressivo, conforme visto nas respostas da questão 67 , mas nem todos o fazem como uma opção 
voluntária, como mostram as seguintes opiniões: "É comum usar (as duas línguas) misturadas, mas é melhor separar o japonês e o português. Quanto a palavras que não têm correspondência, não há jeito." [AM24-91]; "Uso porque me comunico fácil, mas tenho resistência para misturar." [AF44-80]; "É melhor falar sem misturar, se possível, mas não sei falar japonês." [IF55-24]

Há informantes que não valorizam a língua que falam misturando: "Quando falam só japonês, acho muito bonito." [AF55-73]; "Não é muito bonita. Mas não tem jeito" [IF6656]; "Não acho bom (falar assim). Tenho vergonha quando falo com os japoneses. Para eles, deve ser dificil de entender, mas, quando misturamos as duas (línguas), fica mais fácil para nós" [IF58-16]. As opiniões demonstram uma visão da língua japonesa 'ideal' e bonita, e a consciência de norma da língua, o que levam a adotar valoração negativa da língua que falam, mas mesmo assim, não deixam de admitir a facilidade que a mesma proporciona para estabelecer a comunicação entre os falantes da mesma comunidade.

Sanseis - o que se percebe nas respostas dos informantes de terceira geração, com maior escolaridade no Brasil e alta proficiência em português dentre as três gerações, é o contato maior com a língua portuguesa e menor com a japonesa: "Como não uso (o japonês) diariamente, acabo misturando (o português)." [IM23-23].

Os motivos mencionados pelos sanseis que aprovam a mistura de línguas são, em primeiro lugar, a naturalidade; e em segundo, a facilidade e rapidez na comunicação, já mencionadas nas gerações anteriores.

Há opiniões de sanseis que atestam usar o português para suprir a falta de competência em japonês, assim como o exemplo mencionado no parágrafo anterior: "Não sei bemo japonês, e quando há palavras que não sei, acabo misturando o português" (AF42-50); "Quando falo às vezes em japonês e esqueço (a palavra), acaba ficando em português.” (IF20-13).

Há informantes que aprovam a mistura de línguas como uma forma de treinar a lingua japonesa: "Acho bom. Se falar misturando, não esqueço o japonês e é fácil de entender." [AM27-28], "misturando, não esqueço o japonês, (...) mesmo que seja um pouco o japonês fácil de entender, seria um treino, uma prática" [AM35-90]. São opiniões que evidenciam mais uma vez que sua prática em japonês é menor, e nestes casos, expressam também a sua valorização. Ainda, há informantes com as seguintes opiniões: "É significativo. Mesmo que misture, dá para usar o japonês."[AF31-18]; "É melhor que tenha pelo menos um pouco de japonês do que falar tudo em português." [IM19-14], "Quando falo com filhos, falo mais vezes misturando, porque quero ensinar japonês." [AF32-71] demonstrando claramente uma atitude favorável ou de valorização da língua japonesa ${ }^{7}$

7. Exemplo mencionado também por Doi (2007), como expressão da identidade de nikkei brasileiro. 
Por outro lado, há os que manifestam a opinião desfavorável com relação à mistura de línguas na fala: "não é fala correta, mas é habitual entre os nikkeis brasileiros." [AF27-72], opinião em que a informante demonstra consciência da norma linguística, segundo a qual a mistura com outras línguas não é considerada "correta" Outro informante acha "estranho e esquisito, mas não há outra forma para falar com os isseis" [IM46-85]; e um outro responde: "não acho bom, mas não tenho segurança (no japonês) e acabo misturando." [AF28-34]. Nos dois últimos casos, os informantes não aprovam a mistura, mas a pratica para estabelecer a comunicação com os isseis, que têm fluência maior em japonês. As opiniões, mesmo não favoráveis para a mistura de línguas, admitem, nestes casos, a importância que a língua "mista" tem, enquanto um meio de comunicação intergeracional, principalmente com os isseis.

A partir das respostas obtidas nas questões 67 e 68, tentamos traçar os perfis de três gerações, e percebemos que a grande maioria apontou como natural, normal e espontânea a fala com mistura de línguas japonesa e portuguesa, conforme já apontado por Doi (2007), embora a natureza dessa 'mistura' não fique tão clara nessas opiniões emitidas. De todas as formas, sabe-se que a geração que mais respondeu misturar as duas línguas na fala foi a de nisseis, seguida de sanseis e isseis.

Quanto às opiniões sobre a prática de misturar línguas, ou seja, o uso de 'língua da colônia' [koronia-go], não há consenso entre as gerações de duas comunidades pesquisadas, mas em média, os isseis aceitam mais a mistura de línguas, e tentam falar de modo que as outras gerações entendam seu japonês, considerado dificil, misturando o português. Foi também parte dos isseis quem mostrou-se valorizar a língua da colônia, o koronia-go, projetando nela uma identidade linguística.

Os nisseis, com sua competência bilíngüe maior no geral, têm um comportamento lingüístico mais complexo dentre as três gerações, com formas de falar diferenciadas conforme o interlocutor e, apesar de ser a geração que mais mistura, tem também uma parcela com resistência a essa prática, considerando a 'língua da colônia' a forma "não correta"

Já os sanseis, a mais nova geração entre as três pesquisadas, tentam suprir a falta ou o esquecimento de palavras em japonês, usando o português, para falar principalmente com os isseis. Apesar de seu contato menor com o japonês entre todas as gerações pesquisadas, percebe-se numa parcela a valorização da língua japonesa, enquanto numa outra parcela a não-aprovação da mistura de línguas, por diversas razões.

Mas há um consenso entre uma parcela considerável de três gerações de que a 'língua da colônia' é um meio de comunicação entre as diferentes gerações ou entre os que têm diferentes competências linguísticas em japonês e português. Mesmo os que não gostam de misturar as línguas, a maioria o faz, levando em conta o interlocutor, o que comprova que a 'língua da colônia' é um meio indispensável para o estabelecimento de 
comunicação entre as gerações nas comunidades rurais pesquisadas. É importante, nesse sentido, o papel dessa língua hoje na comunidade nipo-brasileira, já num contexto bastante diferente de quando foi denominado, pela primeira vez, na década dos 50 .

Buscamos, neste artigo, descrever a percepção das três gerações nipo-brasileiras sobre a 'língua da colônia' a partir das opiniões dos próprios falantes, com o objetivo de elucidar uma parte de seu hábito lingüístico e tentar compreendê-los dentro de um determinado contexto social. Devemos ressaltar, contudo, que as considerações acima expostas se restringem a duas comunidades rurais do Estado de São Paulo, o que pode não refletir o perfil de toda a população nipo-brasileira, cuja proporção de residentes na zona urbana, hoje, é bastante considerável.

Bibliografia

CENTRO DE ESTUDOS NIPO-BRASILEIROS. (2002) Nikkei shakai jittai chôsa hôkokusho (Relatório das pesquisas sociais das comunidades nipo-brasileiras). São Paulo, Centro de Estudos Nipo-Brasileiros.

DOI, E.T.(2007) Atitude de imigrantes japoneses e descendentes em relação ao japonês falado nas comunidades Nikkei. In: KLEIMAN, A.B. \& CAVALCANTI, M.C.(orgs.) Lingüistica Aplicada - suas faces e interfaces. Campinas, Mercado de Letras.

GAIKO FORUM (2007) "Shiryôhen: Nichi, Chûnanbei kankei" (Dados: Relações entre o Japão e a América Central e do Sul). In Gaikôforum (Forum on Foreign Affairs). Oct.207, no. 231. Tóquio, Toshi Shuppan Kabushikigaisha.

OSAKA UNIVERSITY (2003) The 21st. Century COE Program Interface Humanities Resarch Activities 2002, 2003. Gengo no sesshokuto konkô - Nikkei burajirujinno gengono shosô ( $O$ contato linguistic e a coexistência - diferentes aspectos lingüísticos dos nipo-brasileiros. Osaka, Osaka University.

--- (2004). Memoirs of the Graduate School of Letters Osaka University. Vol. XLIV-II. Osaka, Osaka University.

OTA, J. \& GARDENAL, L.M.S. (2006) O uso das línguas japonesa e portuguesa em duas comunidades nipo-brasileiras: os domínios e a relação com as gerações. Estudos Lingüísticos. Vol. XXXV. São Paulo, Grupo de Estudos Linguisticos do Estado de São Paulo (Gel), p. 1062-1071.

$\mathrm{http}: / / \mathrm{www} .100 \mathrm{nen} . \mathrm{com} . \mathrm{br} / \mathrm{ja} / \mathrm{fukuhaku} /$ (acesso em 11.01.2009) 